\title{
Intervention Model of Perceptual Motor Development in Preschool Children Movement Development
}

\author{
Hari Amirullah Rachman \\ Faculty of Sport Sciences \\ Universitas Negeri Yogyakarta \\ Yogyakarta, Indonesia \\ hari_amirullah@uny.ac.id \\ Sujarwo \\ Faculty of Sport Sciences \\ Universitas Negeri Yogyakarta \\ Yogyakarta, Indonesia \\ jarwouny@gmail.com
}

\author{
Yudanto \\ Faculty of Sport Sciences \\ Universitas Negeri Yogyakarta \\ Yogyakarta, Indonesia \\ yudanto@uny.ac.id \\ Sudardiyono \\ Faculty of Sport Sciences \\ Universitas Negeri Yogyakarta \\ Yogyakarta, Indonesia \\ sudardiyono@gmail.com
}

\begin{abstract}
- this study aims to improve preschool children movement development by producing an intervention model of perceptual motor development. Steps to be followed in this developmental research include: (1) Introduction study, (2) Planning, (3) Improving the first product, (4) The first trial, (5) Revision for arranging the main product, (6) The trial of the main field, (7) Revision of operational product, (8) The trial of operational product, (9) Revision of final product, and (10) The dissemination and the implementation of product. The research trial was conducted at three Kindergartens which consisted of students aged 4-6 years old. The small scale trial was done in 17 kindergarten students while the large scale trial was done in $\mathbf{4 2}$ Kindergarten students. The instrument of data collection of this research consisted of 3 instruments; covered games design, model factor and material inside. Data analysis technique consisted of quantitative descriptive data analysis technique and qualitative descriptive data analysis technique.The results show thirteen activities of perceptual motor intervention model to develop preschool children movement. The game model consists of (1) the game of agility, (2) the game of flexibility, (3) the game of balance, (4) the game of body awareness, (5) the game of spatial awareness, and (6) the game of temporal awareness, and (7) the game of coordination. The specification product from this experimental results can be used as a reference for teaching material in order to develop preschool children movement or a manual book. The book was appropriate with the curriculum and characteristic, and also effective and feasible to be applied as media for developing preschool children movement quality.
\end{abstract} children

Keywords -intervention model, perceptual motor, preschool

\section{INTRODUCTION}

As a human, movement is a distinctive feature of living creature. It shows the human capability to explore their environment indefinitely and also as a medium to overcome problems of life. This means that humans live by making movement. Movement is an integral part of humans. The essence of movement is reflected by the pattern following its growth and development. The growth and development of movement is concurrently giving opportunities to improve the functions of (a) intellectual functions, (b) percepetual sensomotoric functions, (c) emotional psychological functions, (d) socialization or social functions.

Movement development is a continuous change in motor behavior that occurs throughout the human life cycle and is affected by task demands, biological aspect and environment. Any movement, however simple is a result of complex interaction patterns of different parts and systems in the body that are controlled by brain. Basically, this growth is in line with the maturity of the children nerves and muscles system. However, the development of each child is not similar and depends on their process of maturity.

As mention above, every child has a different movement development and in some cases the difference is so big that it makes the parents worried. Therefore, the assessment of children's development needs to be understood by parents. It includes five aspects of functional development namely, gross movements; fine movement; observation; talk; and socialization. Limitations in one aspect can affect other aspects abilities.

Preschool is a golden age in the developmental range of an individual's movement. In this period, children experience a remarkable growth in terms of physical motor, emotional, cognitive and psychosocial abilities. The development takes place in a holistic process so, the provision of stimulation should take place in holistic activity. Here, stimulation is necessary because not all children have normal movement development. Based on the research done by Rachman and Anggita [1], it is known that there are approximately $30.19 \%$ of preschool children who were ranked below good in category for their gross motor skills, and $57.55 \%$ in case of fine motor skills were below good in the category, as shown in the following table 1. 
TABLE I. FREQUENCY DISTRIBUTION OF GROSS MOTOR SKILLS OF PRESCHOOL CHILDREN

\begin{tabular}{|c|c|c|c|}
\hline \multirow{2}{*}{ Range } & \multirow{2}{*}{ Category } & \multicolumn{2}{|c|}{ Frequency } \\
\hline & & Absolute & $\%$ \\
\hline$\leq 63$ & Very Bad & 0 & $0.00 \%$ \\
\hline $64-73$ & $\mathrm{Bad}$ & 2 & $1.89 \%$ \\
\hline $74-83$ & Moderate & 30 & $28.30 \%$ \\
\hline 84-93 & Good & 55 & $51.89 \%$ \\
\hline$>83$ & Very Good & 19 & $17.92 \%$ \\
\hline \multicolumn{2}{|c|}{ Total } & 106 & 100 \\
\hline
\end{tabular}

TABLE II. FREQUENCY DISTRIBUTION OF FINE MOTOR SKILLS OF PRESCHOOL CHILDREN

\begin{tabular}{|c|c|c|c|}
\hline \multirow{2}{*}{ Range } & \multirow{2}{*}{ Category } & \multicolumn{2}{|c|}{ Frequency } \\
\hline & & Absolute & $\%$ \\
\hline$\leq 40$ & Very Bad & 2 & $1.89 \%$ \\
\hline $41-51$ & $\mathrm{Bad}$ & 6 & $5.66 \%$ \\
\hline $62-72$ & Moderate & 53 & $50.00 \%$ \\
\hline $73-83$ & Good & 38 & $35.85 \%$ \\
\hline$>84$ & Very Good & 7 & $6.60 \%$ \\
\hline \multicolumn{2}{|c|}{ Total } & 106 & 100 \\
\hline
\end{tabular}

The recommendation of the research results above is a further assessment on the development of preschool children by providing stimulation to assist them to achieve the progress based on the proper development stage. The provided stimulation is in the form of perceptual-motor interventions given to preschool children in physical activity in school to ensure the movement development is suitable with the developmental stage of preschool children.

Perceptual motor in the development of children movement encourage the children to explore the knowledge of their environment. It is then formulated into a concept which is expressed in the form of movement skills. A child who moves easily and shows skillful movement tends to have positive self-concept and high self-confidence. Cratty argues that children who can not control their movements well usually have low self-concept and often have difficulty to adjust either socially or emotionally [2]. Furthermore, Edwards $^{6}$ states that children who show difficulties in studying in school in the first grade to third grade also have problem in their perceptual motor development and it fundamentally affects their learning achievement. This claim is in line with previous opinions that motor perceptual ability influences cognitive function, i.e. (1) there is a direct effect and correlation between motor perceptual ability and academic achievement, (2) perceptual motor ability is based on readiness and academic performance. For example, a good synchronization between hands and eyes is a requirement for writing skills [3]. Siedentop, Herkowitz and Rink [4] suggest that motor perceptual development is closely related to the range of basic skills or the crucial abilities in building a strong foundation for high learning achievement. So, it can be assumed that any response that occurs due to interaction with the environment can produce a motor perception response. Some responses may be more complex than other responses but, essentially, perceptual motor ability is a behavior that is displayed by involving the ability to interpret all information (visual, kinesthetic, audio and touch) that enter the central nervous system.

Motor perception is the ability produced from interaction with the environment involving the process of movement and observation. Motor perception is a term used to associate between cognitive function and movement skills on children. The concept of motor perception refers to the retrieval of information which is obtained from the environment to produce motor behavior. The movement generated from the perception process depends on the information processing system that exists within the human being. The ability of motor perception can affect other abilities in human life, such as cognitive function, academic competence, social and emotional development, and self-concept. Motor perception, formed by the components of movement cover, (1) body understanding, (2) space understanding, (3) movement quality, (4) direction understanding (5) time structure understanding, and (6) connection with object beyond the body.

Similarly, in terms of children, motor intelligence is influenced by other aspects of development, especially the connection of physical and intellectual of children. The question that needs to be answered, i.e to what extent does perceptual motor interventions foster the children's movement? How is the intervention pattern? How is the intervention done to find out the developmental stage of children's movement?

The model of interventions for the development of preschool children's movement is based on: (1) the phenomenon of the children movement development which is not in accordance with the proper stage; (2) the curriculum has not guaranteed the effectiveness of teachers in preschool; (3) the teacher's lack experience, coaching and training on how to teach or transfer movement development materials for preschool children; (4) children feel bored when given learning activities in the classroom; (5) limited equipment that can be used as learning media; and (6) the model of movement developmental intervention that integrates motor perceptual activity in preschool children has not been developed yet. The framework of the game model of movement development interventions for preschool children can be seen in the figure below. 


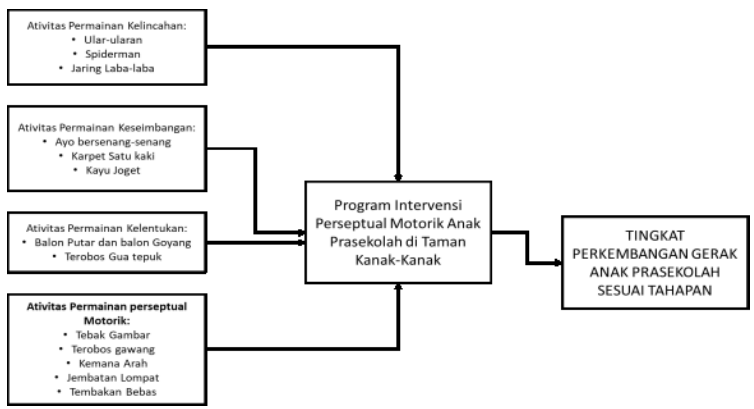

Fig. 1. Framework of Intervention Model of Movement Development for Preschools Students.

Based on the description above, the observation facts, and the interviews results, this research attempts to provide solutions to develop the movement of preschool children through the game activities that have been mentioned above. It is expected that through the game model which integrates perceptual motor activity the learning becomes more attractive, communicative, and stimulating the development of preschool children's movement. So, all experiences that children during preschool can be useful for their future.

\section{METHODS}

This study can be catagorrized as research and development $(\mathrm{R} \& \mathrm{D})$ to produce educational product. $\mathrm{R} \& \mathrm{D}$ is a process to validate and develop educational products in the form of goods, procedures, and learning methods. Based on Gall \& Borg [5], this kind of research uses the research findings to design new products or procedures that is then systematically tested in the field. It is followed by evaluation and refinement to meet certain criteria in case of its effectiveness and usefulness. The implementation of the development procedure in this study adapted the educational research and development stages by Gall \& Borg [5]. The research scheme is presented in Figure 3.

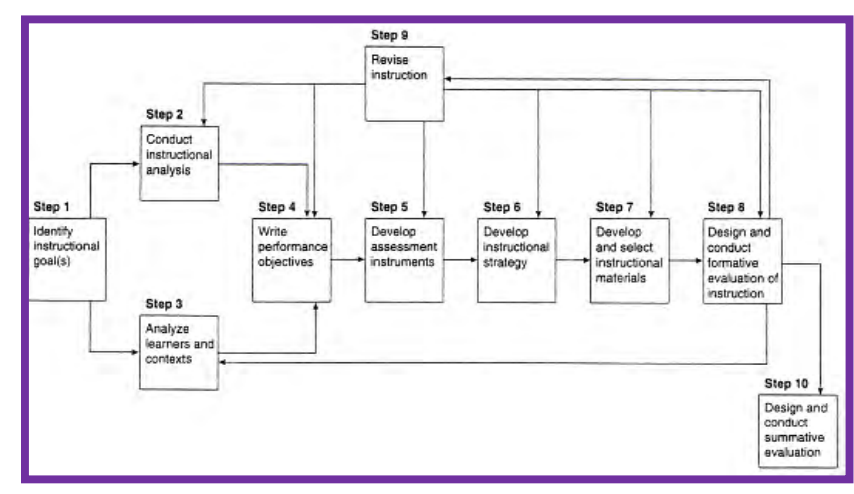

Fig. 2. The Scheme of the Research Procedure and Development [5]

The research and development stages of Gall \& Borg [5] cover the following: (1) assessing the need to identify objectives; (2) conducting instructional analysis; (3) analyzing students and materials; (4) writing performance goals; (5) developing assessment instruments; (6) developing instructional strategies; (7) developing and selecting instructional materials; (8) designing and conducting formative evaluation of learning; (9) revising instructions; and (10) designing and conducting summative evaluation. By through those ten steps, an effective and well-implemented final product can be produced. From the ten steps of research and development above, this study only employed 9 stages, namely: (1) assessing the need to identify objectives; (2) conducting instructional analysis; (3) analyzing learners and materials, (4) writing performance goals, (5) developing assessment instruments; (6) develop instructional strategies; (7) developing and selecting instructional materials; (8) designing and conducting formative evaluation of learning; and (9) revising the instructions.

The trial was done to improve the game model by practicing it directly in the field. Product or game trial was done twice, in small and large-scale field. Prior to the trials stage, the game draft was assessed and validated by media experts, materials experts and practitioners to ensure its feasibility for field trial.

The role of the media expert was to direct the point of view and clarity of game instruction in video making. The role of the material expert was to observe the feasibility of the game draft with the facts and conditions in the field while the practitioner was also to observe the feasibility of the draft game prepared by researchers with the fact and circumstances in the field. After large-scale field trials were conducted, the output of this development study was to produce a guidebook and game tool for the development of perceptual-motor skills that was feasible and valid among preschool students.

Data analysis techniques was done uisng descriptive qualitative and quantitative analysis. Quantitative descriptive analysis was done to analyze the following data: (a) observer data / observations of material experts, media experts, and practitioners of the game model for the development of preseptual motor interventions of preschool children; (b) scale scores data from expert material, media experts, and practitioners for the model validation; (c) observation data of experts and practitioners on the effectiveness of the model (d) the data of the practitioner's observations on the children developmental achievement level including three learning domains (affective, psychomotor, and cognitive) during the learning process, the practitioner's assessment used the star icon $(*)$ which was enclosed in the assessment rubric of appendix 3; and (e) data on practitioners' observation of the children response during the lesson. Qualitative descriptive analysis, meanwhile, was conducted on: (a) field note data and (b) data suggestion to improve the game model for development of perceptual motor intervention of preschool children before or after field trial.

The initial draft of the game model was feasible for smallscale field trials if the experts of media, material and the practitioners had validated and stated that all classification items on the scores scale are considered "appropriate" by 
ticking $(\sqrt{ })$ on the appropriate / very appropriate box. In this case there were four types of score, i.e. 1 for "not appropriate" category; 2 for "moderate"; 3 for "appropriate" and 4 if it is declared "very appropriate". If the experts or the practitioner classified the item as "not appropriate", it was followed by review for the product revision process. The model was considered feasible to be tested for small-scale rials and large-scale field trials if the quantitative scores reached the minimum feasibility standards. The calculation criteria of score conversion guidance or normative categorization was presented in the following table.

TABLE III. CALCULATION OF NORMATIVE CATEGORIZATION

\begin{tabular}{|c|c|c|}
\hline Formula & Limitation & Catagory \\
\hline $\mathrm{X}<(\mu-1,0 \sigma)$ & $\mathrm{X}<20$ & $\begin{array}{c}\text { Low (Less Appropriate / } \\
\text { Less Effective) }\end{array}$ \\
\hline $\begin{array}{c}(\mu-1,0 \sigma) \leq \mathrm{X}< \\
(\mu+1,0 \sigma)\end{array}$ & $20 \leq \mathrm{X}<30$ & $\begin{array}{c}\text { Moderate (Quite } \\
\text { Appropriate) }\end{array}$ \\
\hline$(\mu+1,0 \sigma) \leq \mathrm{X}$ & $30 \leq \mathrm{X}$ & $\begin{array}{c}\text { High ( Appropriate } \\
\text { /Effective) }\end{array}$ \\
\hline
\end{tabular}

\section{RESULT}

The model of movement development for preschool children consists of four activities, namely: (1) Balance Games; (2) Agility Game; (3) Flexibility Game and (4) Motor-Perceptual Game. Those four components were developed into 13 game activities. The game activities developed in this model are: (1) Fun Snake game that aims to train the students' agility by passing through the pipe. This game was done in groups and could also be contested. This game can be used to develop cooperation, and competitive attitude of students; (2) Fun Spider game aims to develop the students' concentration; (3) Me and You game that aims to understand the rules and disciplines matching with the game conditions; (4) Spiderweb game that aims to improve agility, flexibility, foot coordination, speed, balance, and reaction; (5) Basketball game that aims to develop an attitude of appreciating the superiority of others in the game; (6) Balance Bridge game that aims to train the students' balance. This game is done in groups and can also be used to train the sportsmanship, honesty, and students' thoroughness on movement learning; (7) Carpet Relay (estafet) game focuses to train the students balance. This game is done individually but can be in the form of competition and it also be used to train the students concentration in movement learning; (8) Wood Dance game emphasizes to train the students' balance. This game is done individually and can be used to train the students' concentration in movement learning; (9) Turned Balloon and Balloon game aims to train the formation of waist and back of students. It is done in groups and can be in the form of competition. This game can also be used to develop cooperation, and sportsmanship; (10) Clap Cave Through aims to train the waistline and back of students, and can be contested. This game can be used also to develop sportsmanship; (11) Picture Guessing is a game that aims to stimulate learners' minds about the students' perception in understanding various animals; (12) Fun Obstacle Run aims to develop awareness of space and direction as well as the children's competitive attitude; (13) Rope Climbing aims to develop coordination, balance, and quality of movement.

The assessment from media experts, material experts and practitioners showed that, games used to develop preschool children's movement can be catagorized "Good" if the sum of score for each game was in the interval of " $30 \leq X "$. It means that the game model for the development of preschool children's movement was easily practiced by the teacher, the required equipment easily obtained and are safe and lovable. The game also attracted the children attention which was suitable with the characteristics of preschool students, and it can develop their perceptual motor skills.

The assessment from material experts and practitioners showed that the game was effective as a learning medium to develop preschool children's movement as in the case of (1) all thirteen game activities can be used as a learning medium to transfer cognitive, affective, and psychomotor domains in accordance with the curriculum and characteristics of preschoolers; and (2) reflection of results from practitioners or Kindergarten teachers on the level of children development achievement indicated that the children's movement development was good. This positive development can be seen from the frequency distribution of the children's development assessment by teachers towards 13 movement development activities i.e there was no child or $0 \%$ for the undeveloped category in every movement development.

The trail subject and all children subjects responded positively to the game of emotional social development. The students of B group kindergarten gave "Smile" to any game activity they did. Smile responses indicated that the children were happy to follow the teacher's lesson.

\section{DISCUSSION}

This study resulted in the form of intervention model for movement development among preschool students including four parts, namely: (1) Agility Games Activities; (2) Balance Game Activities; (3) Flexibility Game Activities (4) Motor Perceptual Game Activities. Based on those four components, it was developed into 13 game activities that mostly use gross motor activity emphasizing on the development of bone, muscles and the ability to move and manipulate the environment. In accordance with the opinions of Bowlby and Ainsworth ${ }^{9}$ that movement development also includes how the muscles of children work well or called muscle balance, children need balanced muscles to develop their muscle system so it can be used easily when standing, sitting, rolling, walking, running, swimming, and any other activities.

Movement development activity begins with agility activity (the ability to change the direction and position of the body quickly and precisely while moving without loss of 
balance and awareness of the body position). The direct benefits of agility activities include (1) coordinating multiple movements (stimulation); (2) facilitating the skills acquisition that require speed of coordination: (3) facilitating the environment orientation. It is supported by Coleman ${ }^{4}$ that if children want to have successful development in movement skills, they must receive many physical opportunities to explore their environment.

The next activity is about balance. This aspect is one of the required factors for children to perform effective and efficient movement. Good balance enables a person to perform effective and efficient activities or moves with minimal risk of fall. Balance is the ability to maintain the center of gravity, usually when the children are in erect position. In this study, the balance game activity is built to explore and to develop children balance through encouraging activity in accordance to Poppe [6]. He claims that the key to improving your child's balance, or any other portion of their fitness, is to keep the exercises / games fun. The more they enjoy themselves, the more they'll want to do.

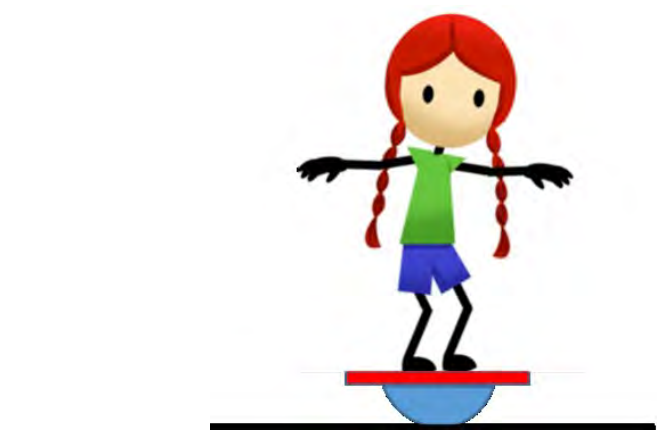

Fig. 3. Wood Dance Game

Flexibility activity aims to train the formation of the students' waist and back. This game is done in groups and can be in the form of competition with the scope of the activity as (1) stretching the joints and (2) relaxing muscles group. This formation is necessary for every child, to make them easy to learn various moves, to improve skills, ro reduce the risk of injury, and to optimize strength, speed and coordination. The game can be used to develop cooperation, and sportsmanship in which the ability of body to perform exercises with large or extensive amplitudes. In accordance with the opinion of Allen and Marotz ${ }^{1}$ that flexibility refers to the range of motion around a joint it can be explained that the skeleton is the ability of the wrist or joint to perform the movement of all directions with the large and broad amplitude of the movement (movement range) based on the function of the moved joint. Other terms for flexibility are, elasticity and suppleness. Flexibility is one of the crucial elements of physical condition to improve movement skills, to prevent injury, to develop strength, speed, endurance, agility and coordination.

Perceptual motor activity was arranged in the form of post-game in which each learner must be able to think, to concentrate and to move according to the game series. Consecutively, the first post was picture guessing, the next was body and space awareness game, the third was balance, fourth was consciousness directions, and the fifth post was coordination and movement quality. Perceptual motor is the ability to interpret the stimulus received by the sense organs. According to Gibson, perceptual motor skill is the person ability in describing the stimulus or psychological objects such as ideas, events or specific situations caught by the five senses (taste, smell, feel, sight and hearing) separately or simultaneously to get a clear picture or response about the received stimuli as the basis of one's behavior. Gallahue ${ }^{5}$ states that the quality of a person's movement development depends on perceptual motor. In this regard, in the giving of examples of the execution of the task of motion, the students' ability to perform the task depends on their ability to obtain information and interpret the meaning in the form of movement.

The movement development is strongly influenced by the perceptual motor skill that underlies every child's movement. The more mature development of the brain's nervous system that regulates the muscles to the development of movement competence or children motor abilities. This is in line with the view from Siedentop, Herkowitz and Rink [4] that, the development of perceptual motor is closely related to various basic skills or abilities that are believed to have important role to build a strong foundation of high learning achievement. It can be assumed that any response due to perceptual motor intervention can result in movement development response, in accordance with Magill [7] who suggests that some responses may be more complex than other responses, but essentially, perceptual motor behavior is represented by involving the ability to interpret all information (visual, kinesthetic, audio and touch) that enters the central nervous system.

The conclusion of this study is that the intervention towards the development of preschool movement is very important and can be done through the model of game activity involving perceptual motor skills. This model combines balance, flexibility and coordination that is presented in an interesting, creative, and competitive way.

\section{REFERENCES}

[1] H.A. Rachman, G. M. Anggita, "The development pattern of early age children's motor skills". Journal of Physical Education, Sport, Health and Recreation, 2018, vol. 7, no. 2, pp. 104-112.

[2] L. A. Kurtz, "Understanding motor skills in children with dyspepsia". ADHAM, Autism, and Other Learning Disabilities, 2007.

[3] M. L. Latash, F. Lestienne, "Motor control and learning". New York, Springer, 2006.

[4] D. Sidentop, J. Herkowitz, J. Rink, "Elementary physical education methods". Englewood Cliffs, NJ, Prentice Hall, 1984.

[5] M.D. Gall, J.P. Gall, W. R. Borg, "Educational research: an introduction $8^{\text {th }}$ ed." Boston, Pearson Inc, 2007.

[6] L. Poppe, "Activities and games to increase balance for toddlers". Available at http://parentsavvy.com/authors/Lisa-Poppe?id=32, 2018.

[7] A. R. Magil, "Motor learning concepts and applications". Dubuque: Wm.C.Brown Company Publishers, 2005. 